\title{
Effect and cost of two successive home visits to increase HIV testing coverage: a prospective study in Lesotho, Southern Africa
}

Niklaus Daniel Labhardt ${ }^{1,2,3^{*}}$ (D) Isaac Ringera ${ }^{4}$, Thabo Ishmael Lejone ${ }^{4}$, Alain Amstutz ${ }^{1,2,3}$, Thomas Klimkait ${ }^{3,5}$, Josephine Muhairwe ${ }^{4}$ and Tracy Renee Glass ${ }^{1,3}$

\begin{abstract}
Background: Home-based HIV testing and counselling (HB-HTC) is frequently used to increase awareness of HIV status in sub-Saharan Africa. Whereas acceptance of HB-HTC is usually high, testing coverage may remain low due to household members being absent during the home visits. This study assessed whether two consecutive visits, one during the week, one on the weekend, increase coverage.

Methods: The study was a predefined nested-study of the CASCADE-trial protocol and conducted in 62 randomly selected villages and 17 urban areas in Butha-Buthe district, Lesotho. HB-HTC teams visited each village/urban area twice: first during a weekday, followed by a weekend visit to catch-up for household members absent during the week. Primary outcome was HTC coverage after first and second visit. Coverage was defined as all individuals who knew their HIV status out of all household members (present and absent).

Results: HB-HTC teams visited 6665 households with 18,286 household members. At first visit, 69.2 and $75.4 \%$ of household members were encountered in rural and urban households respectively $(p<0.001)$ and acceptance for testing was $88.5 \%$ in rural and $79.5 \%$ in urban areas $(p<0.001)$, resulting in a coverage of 61.8 and $61.5 \%$, respectively. After catch-up visit, the HTC coverage increased to $71.9 \%$ in rural and $69.4 \%$ in urban areas. The number of first time testers was higher at the second visit $(47 \%$ versus $35 \%, p<0.001)$. Direct cost per person tested and per person tested HIV positive were lower during weekdays (10.50 and 335 USD) than during weekends (20 and 1056 USD).
\end{abstract}

Conclusions: A catch-up visit on weekends increased the proportion of persons knowing their HIV status from 62 to $71 \%$ and reached more first-time testers. However, cost per person tested during catch-up visits was nearly twice the cost during first visit.

Trial registration: NCT02692027 (prospectively registered on February 21, 2016).

Keywords: HIV, Home-based, Testing, Door-to-door, Coverage, Community-based testing

\footnotetext{
* Correspondence: n.labhardt@swisstph.ch; n.labhardt@unibas.ch

'Department of Medicine, Swiss Tropical and Public Health Institute, Basel, Switzerland

${ }^{2}$ Infectious Diseases and Hospital Epidemiology, University Hospital Basel,

Basel, Switzerland

Full list of author information is available at the end of the article
}

(c) The Author(s). 2019 Open Access This article is distributed under the terms of the Creative Commons Attribution 4.0 International License (http://creativecommons.org/licenses/by/4.0/), which permits unrestricted use, distribution, and reproduction in any medium, provided you give appropriate credit to the original author(s) and the source, provide a link to the Creative Commons license, and indicate if changes were made. The Creative Commons Public Domain Dedication waiver (http://creativecommons.org/publicdomain/zero/1.0/) applies to the data made available in this article, unless otherwise stated. 


\section{Background}

High coverage of antiretroviral therapy (ART) to achieve viral suppression in people living with HIV/AIDS is a cornerstone of the UNAIDS strategy to end AIDS by 2030 and is defined in the 90-90-90 targets [1]. Universal awareness of HIV status through broad HIV testing is the front door to this strategy [2]. In South-Eastern Africa, the region most heavily affected by the HIV epidemic, the percentage of people living with HIV who know their status has been steadily increasing over the last years and, according to UNAIDS, by the end of 2017 was estimated $81 \%$ [3].

Providing home-based HIV testing and counselling (HTC) is a well-established approach to reach individuals who do not seek testing at health facilities and to increase testing coverage in the population $[4,5]$. In a metaanalysis that included 31 studies of home-based HTC, pooled uptake - acceptance of HTC - was 82\% [6]. However, even where uptake may be high, coverage often remains low as home-based HTC misses all those individuals who are absent during the home visit. This may particularly affect working household members and children and adolescents going to school since most home-based HTC campaigns are conducted during regular workinghours. In their meta-analysis, Sharma and colleagues estimated coverage achieved through home-based HTC. Of the identified 16 studies reporting on HTC coverage and conducted after 2005, nine were of large scale $\left(>10^{\prime} 000\right.$ individuals) [6]. Coverage rates varied widely from $33 \%$ in a study conducted in Malawi [7] to $96 \%$ in study in Kenya [8]. More recently, the SEARCH project, which used a hybrid approach of mobile clinics and home-based testing, achieved 91 and 87\% testing coverage in Ugandan and Kenyan regions, respectively [9].

Lesotho, a small landlocked country surrounded by South Africa, has the second-highest HIV prevalence globally (adult HIV prevalence 23.6 [21.2-24.7]) [10]. In $2014,63 \%$ of adult women and $38 \%$ of men reported having had an HIV test in the last 12 months, and according to 2017 UNAIDS estimates $72 \%$ were aware of their status in 2016 [11]. In a cluster-randomized trial, home-based HTC had an acceptance rate of $92.5 \%$. However, this trial did not assess coverage, and the rather low HIV prevalence among those tested through home-based HTC suggests that mostly household members with lower risk of exposure had been reached in this trial [12].

Here, we report HTC coverage achieved through a new home-based HTC strategy where households are visited twice - first on a workday and then on a weekend day in order to catch household members absent during the week.

\section{Methods}

\section{Design}

We report the results of a sub-study of the CASCADEtrial [13]. The here reported sub-study is a predefined nested study of the published protocol of the CASCADEtrial [14]. The major objective of this cross-sectional study is to assess coverage achieved through a two-day homebased HTC. The first visit always occurred during a work day. The second visit was strictly on weekends and aimed at offering HTC to household members who were absent during the first visit. The home-based HTC campaigns were conducted in rural and semi-urban neighborhoods of six catchment areas in Butha-Buthe district in northern Lesotho. For rural areas, villages were randomly selected from a list of eligible villages. To be eligible, a village had to be clearly confined to one of the six catchment areas and to comprise between 40 and 80 households. Catchment areas of the clinics are defined by the district health authorities. In Butha-Buthe town, urban neighborhoods were randomly selected.

\section{Setting}

Butha-Buthe is a mostly rural district with an estimated 110,000 habitants, primarily subsistence farmers, mine workers, or construction and domestic workers in neighboring South Africa. The district has only one small town (Buthe-Buthe, ca. 25,000 habitants), while the remaining habitants live in villages scattered over a partly mountainous surface of $1767 \mathrm{~km}^{2}$. In 2016, the adult HIV-prevalence (15-49 years) was $17.8 \%$ [15]. The district is served by one public, one missionary hospital and 10 health centers. Similar to other high prevalence settings, HTC is provided by lay counsellors [16]. Lay counsellors are persons who completed at least primary education and underwent a standardized 10-day training on how to conduct HTC. They are supervised by a professional counsellor with tertiary education. In our study all participating lay-counsellors were female.

\section{Procedure}

Chiefs of the selected villages and urban neighborhoods were informed prior to the home-visits. From February 22 to July 17, 2016 three teams, each consisting of four laycounsellors, one professional counsellor, one nurse and a driver, visited one village per day. Upon arrival the team members divided up the village assigning a specific area to each lay-counsellor. Lay-counsellors then walked from house to house to propose HTC to all households in their area. The head of household or a substitute (usually the oldest household member present) had to provide written consent before the lay-counsellor could enter. Once inside and behind closed doors, the lay-counsellor first counted all members living in the respective household - present and absent. Every person spending at least two nights per month in the household was defined as household member. This definition was chosen because in Lesotho many family members work in neighboring South Africa and return back home only 1 week-end per month. Once 
information about all members was collected, the laycounsellor proposed HTC to all individuals who were present. HTC was performed according to international and national guidelines [17]. All household members who were not known to be HIV-positive were eligible for HTC. As per guidelines, each individual had to sign the National HTC consent form before being tested. For children below 12 years of age, a caregiver aged $\geq 21$ years had to provide consent. Household members could choose to test in family or separately. Initial testing was done with Alere Determine $\mathrm{e}^{\mathrm{Tx}} \mathrm{HIV}-1 / 2$. In case of a positive result, Trinity Biotech Uni-Gold $^{\mathrm{Tm}}$ was used for confirmatory testing. Once all who accepted HTC were tested, the lay-counsellor announced the week-end day he/she would return to propose HTC to absent household-members. This second visit was always during the following weekend, based on a list with households where members had been absent at first visit. Each lay-counsellor was re-assigned to the same households she had seen during the first round. Members absent at first visit but present at the second visit were proposed HTC. Persons found HIV positive were assessed for eligibility for the CASCADE-trial as outlined in the protocol [14]. Those not eligible were assessed by the nurse and referred to the clinic.

\section{Data and analysis}

The major variable of interest was the HTC coverage achieved in the study areas after first and second visit of home-based HTC. Coverage was defined as the percentage of individuals knowing their HIV status after the home visits (either already known to be HIV infected or tested at one of the two home-visits during the study) out of all household members (encountered and not encountered during the two home-visits). HTC uptake was defined as follows: number of individuals who accepted HTC over all household members encountered at home and who were not known to be HIV positive. In addition to coverage and uptake we assessed time since last test categorizing clients into "never tested before", "tested $\geq 12$ months ago" and "tested $<12$ months ago".

Data-collection was tablet-based using a specifically developed app (Visible Solutions AG, Switzerland, visibleimpact.org). For every household member, the outcome of the HTC home visit was categorized into "not encountered", "encountered, already known to be HIV-positive", "encountered, refused HTC" and "encountered, took up HTC".

Every evening, when the study team had returned to town, data were uploaded from tablets to a bankingstandard ISO 27001 audited data center and deleted from the mobile device.

\section{Statistical analysis}

Data were summarized with frequencies and percentages for categorical data and medians and interquartile ranges
(IQR) for continuous data. Categorical data were compared with chi-square tests and continuous data with Wilcoxon rank sum tests.

Subgroups of apriori interest were children (age $<15$ years of age), male adults, and female adults. Univariable logistic regression models were utilized to test for the association between these three subgroups and presence at home, uptake and coverage. Within the three subgroups, the association between previous testing status and uptake and HIV prevalence was modeled using logistic regression. Results are presented with odds ratios (OR) and 95\% confidence intervals (CI). For HTC uptake and coverage, we further stratified analysis by urban versus rural areas. We further stratified outcome analyses All data analysis was done using Stata version 14 (StataCorp, College Station, TX, USA).

\section{Cost considerations}

In this article we report the retrospective cost-analysis considering direct cost of staff, staff training, equipment and transport while planning and conducting the HTC campaigns. Transport cost included fuel, vehicle insurance, tire replacement, car servicing and repair but not the purchase of the vehicle. The sum of all costs was then divided by the number of persons tested or number of persons newly tested positive. Cost attributed per item is reported in the Additional file 1: Table S1.

\section{Results \\ Participants}

From February 22 to July 17, 2016 counsellors visited 62 rural villages and 17 urban areas. Out of a total of $6660 \mathrm{oc}-$ cupied households, $5(0.08 \%)$ heads of household did not consent to a household visit. The 3800 consenting rural households (median 50 (IQR 27-80) per village) had 11,368 household members (median 3, IQR 1-4 per household). In the urban areas, the 2855 consenting households (median 121 (IQR 67-273) per urban area) had 6968 household members (median 2, IQR 1-4 per household).

\section{Coverage after first visit}

During the first household visit, $69.2 \%$ of the household members in villages and $75.4 \%$ of those in urban areas were at home $(p<0.001)$. Among all 13,119 household members encountered at home during first visit, 1365 (10.4\%) were already known to be HIV-infected. Among the remaining 11,754 who had never tested positive, HTC uptake was $88.5 \%$ in villages and $79.5 \%$ in urban areas $(\mathrm{p}<0.001)$. Overall coverage after first visit was $61.8 \%$ in rural villages and $61.5 \%$ in urban areas $(p=0.74)$.

\section{Coverage after second-visit}

Of the 6655 households surveyed during first visit, 2004 (30.1\%) had absent members and were re-visited on the 
following weekend. Of the 5217 household members absent during the first visit, 1890 (36.2\%) were encountered during the second visit. Just over half of these were children who had mostly been at school (Table 1). Of the 1890 newly present members at the second visit, 56 were known to be HIV positive. Among those who had never tested HIV positive, 1647 (90.4\%) took up HTC (urban $84.0 \%$, rural 93.7\%, $p<0.001$ ). With the second visit, overall HTC coverage increased to $71.0 \%$ (Fig. 1), $69.4 \% \%$ in urban and $71.9 \%$ in rural areas $(p<0.001)$.

Table 1 shows the age and gender distribution of all household members according to their presence during the visits. Table 2 shows the reasons for absence in household members not encountered.

\section{HTC uptake and HIV prevalence}

If encountered at home, overall uptake was $85.3 \%$. Table 3 displays likelihood of being encountered at home and HTC uptake in children, adult women and men. Men and children were less likely to be encountered at home. But if encountered, uptake of HTC was similar.

HIV prevalence among those tested was 0.6, 4.2 and $4.0 \%$ in children, adult women and adult men, respectively (Table 4). Considering persons encountered at home who were already known to be HIV positive and individuals newly diagnosed during home-based HTC, the prevalence among adults aged $15-49$ years was 18.8 , $21.6 \%$ in women and $13.0 \%$ in men.

\section{First-time testers}

Among all individuals encountered, 5337 (39.4\%) were first time testers, and $3462(25.5 \%)$ had tested $\geq 12$ months ago. There was a significant difference in the share of first-time testers between persons tested at first and second visit $(p<0.001)$ : at first visit $34.8 \%$ had never tested before (second visit: $46.9 \%$ ), 31.6\% had their last HIV test $\geq 12$ months ago (second visit: 28.1\%) and $33.7 \%$ had tested $<12$ months ago (24.9\%). First time testers were more likely to uptake HTC compared to those recently tested (OR: 1.30 ; 95\%CI: $1.16-1.44$ ) and less likely than those tested $>12$ months ago (OR: 0.57 ; 95\%CI: 0.50-0.66) (Table 4).

\section{Awareness of HIV status and ART-coverage}

Out of the 1765 individuals encountered who were HIV positive, $1421(80.5 \%)$ already knew their status before the home-based HTC campaign and 1241 (70.3\%) were already on ART.

\section{Cost estimates}

Overall direct costs of the HTC campaigns were USD 137,510; USD 38,322 for senior staff (nurses and campaign organizers); 16,738 for lay-counsellors and drivers; 26,050 for food and accommodation during the campaign as well as small incentives, such as bags, coats and hats; 30,500 for transport (fuel, vehicle repair and maintenance); 25,900 for HIV test kits, IT cost, purchase of tablets and small equipment, such as gloves, needles, etc.

Overall cost per person tested for HIV, and per person newly tested HIV positive was USD 11.8 and 399.7, respectively. Costs were higher during weekend catch-up visits. Per person testing cost were 10.5 and 20.0 during week and weekend days respectively. Similarly, costs per person tested HIV positive was lower during weekdays (335 versus 1056). Differences in cost between weekdays and weekends were driven by a lower average number of persons tested per lay-counsellor on weekend days (3.0 vs 6.6) resulting in higher staff-cost relative numbers tested.

\section{Discussion}

This study tested the effectiveness of a weekend catchup visit to increase home-based HIV testing coverage in rural and urban areas in Lesotho, Southern Africa. After a first home-based HTC visit during a work-day, overall coverage was $62 \%$ and increased to $71 \%$ after a catch-up visit during the following weekend. This increase came at considerable additional cost: Testing a person cost about twice as much during catch-up visits, and cost per person newly tested positive was three times higher due to fewer persons tested per health care worker on weekends. During the catch-up visit, $47 \%$ were first-time testers, compared to $35 \%$ at the visit. While HTC uptake was similar between women and men, coverage was significantly lower in men due to a higher share of male household members who were absent at both visits. In urban areas household members were more likely to be encountered at home but uptake was lower, resulting in

Table 1 Age and gender of household members

\begin{tabular}{lllll}
\hline & $\mathrm{N}$ & Encountered at 1st visit & Encountered at 2nd visit & Not encountered \\
\hline $\mathrm{n}$ & 18,336 & 13,119 & 1890 & 3327 \\
Median Age (IQR) & $25(12-45)$ & $28(14-52)$ & $14(9-25)$ & $19(11-34)$ \\
Women $\geq 15$ years & 7875 & $6671(50.9)$ & $459(24.6)$ & $745(22.5)$ \\
Men $\geq 15$ years & 4807 & $3029(23.1)$ & $436(23.3)$ & $1342(40.5)$ \\
Children $<15$ years & 5604 & $3398(25.9)$ & $978(52.2)$ & $1228(37.0)$ \\
Age/sex missing & $50(0.3)$ & $21(0.2)$ & $17(0.9)$ & $12(0.4)$ \\
\hline
\end{tabular}




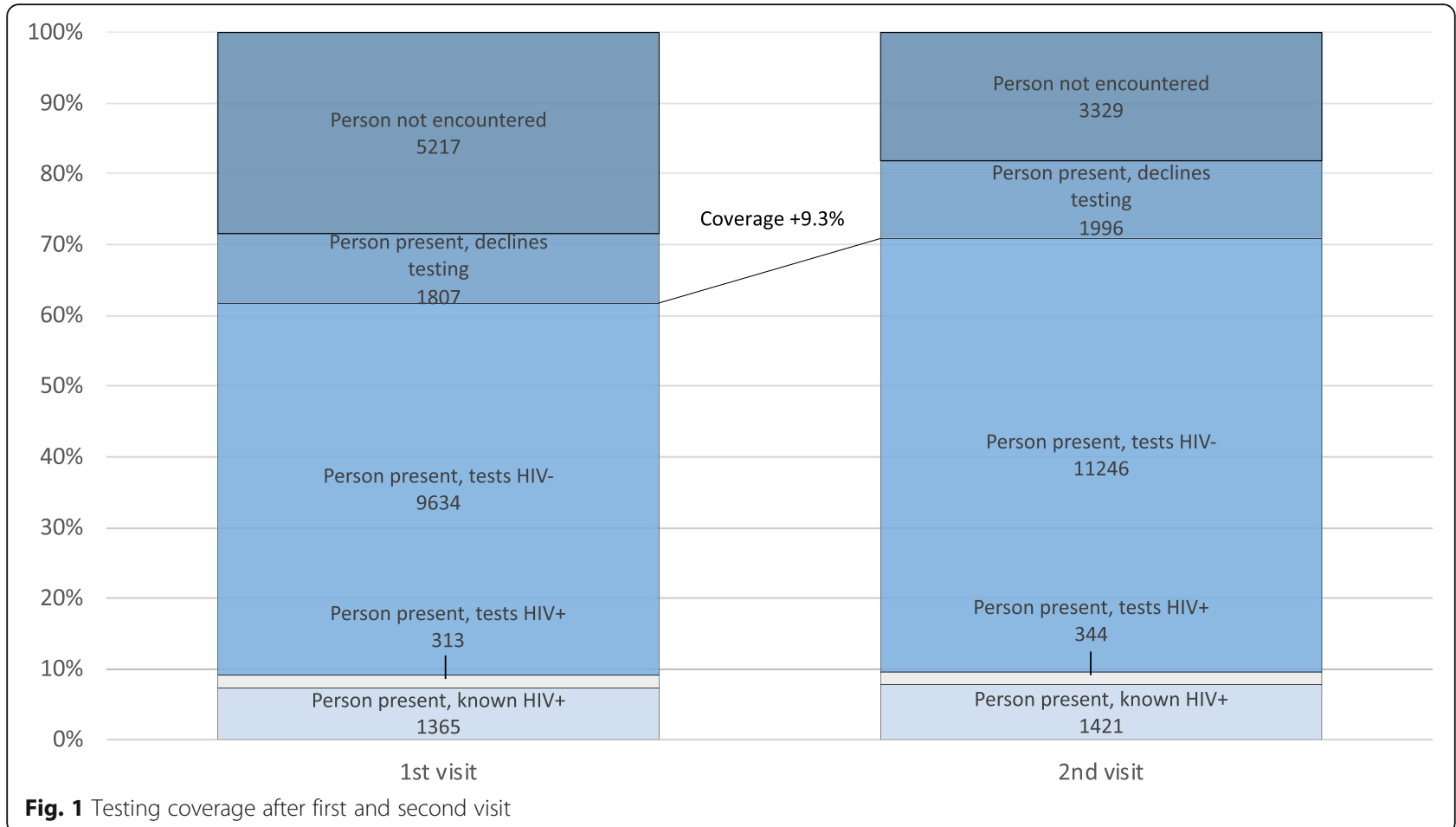

a slightly lower HTC coverage in the urban areas. Although, in this study, targeted catch-up visits improved testing coverage, it still fell short of the targeted 90\% testing coverage, mainly because many household members were absent at both visits.

To our knowledge, this is the first study quantifying the added value of targeted catch-up visits after a first round of home-based HTC. For assessing coverage, we did not rely on census data or extrapolated estimates but directly censored household-members during the campaign. We defined as household members any person sleeping at least two nights per month in that household. This broad definition may have led to a lower HTC coverage compared to other studies. In the SEARCH project HTC coverage was studied among "stable residents", defined as those, "living in the community for at least 6 months in the past year". In Ugandan and Kenyan areas together, the SEARCH project achieved among adults a $89 \%$ HTC coverage, $86 \%$ among men and $92 \%$ among women [18]. Testing coverage among adolescents was $88 \%$ [19]. Another project, conducted in Uganda, calculated coverage based on official census data. In that study, during a period of 6 months, 66 trained community health workers provided home-based HTC to over 40'000 individuals reflecting an estimated HTC coverage of $69.4 \%$ at the end of the project [20].

Whereas in our study direct cost per person tested for HIV was USD 11.8 USD and USD 399.7 per person tested and per person tested HIV positive, respectively. Asiimwe et al. reported from Uganda costs of USD 3 and 136 per person tested and person tested positive, respectively [20]. In the SEARCH, project home-based HTC was more expensive than community health campaigns and came at a cost of USD 31.7 per adult tested and 298.5 per adult tested HIV positive [21]. In line with these reports, our study shows that home-based HTC is a cost-intensive approach. On the other hand, home-based HTC remains a good strategy to reach individuals who might not seek testing at a health facility. In our study, close to $40 \%$ indicated they were testing for the first time, and $25 \%$ stated that their last HIV test was more than 12 months ago. As demonstrated in immunization programs previously, increasing coverage from an already high coverage to the targeted 90\% immunization coverage comes at a higher cost per percentage than increasing from a lower level to $80 \%$ [22]. Similarly, to close the gap from 80 to $90 \%$ HIV testing coverage will need more resources. This is particularly true for remote rural areas, where finding people living with HIV who are not on treatment is time- and resource intensive.

For those encountered at home, uptake of HTC was $85.3 \%$. This is lower than in a previous study conducted in the same setting, where $92.5 \%$ accepted HTC [12]. Possible explanations are that the earlier study provided multi-disease testing and that it was 
Table 2 Reasons for not being at home at first and second visit among household members not encountered (29 are not included in the table due to missing information about sex or age)

\begin{tabular}{lll}
\hline Location of absent household members & First visit & Second visit \\
\hline Women $\geq 15$ years & 1204 & 745 \\
- At school & $318(26.4)$ & $197(26.4)$ \\
- Work, commuting daily & $148(12.3)$ & $115(15.4)$ \\
- Work, home on weekends & $44(3.7)$ & $36(4.8)$ \\
- Work in South Africa & $84(7.0)$ & $80(10.7)$ \\
- In the fields/herding & $36(3.0)$ & $22(3.0)$ \\
- Single day absence (not work-related) & $386(32.1)$ & $256(34.4)$ \\
- On holidays & $23(1.9)$ & $20(2.7)$ \\
- No information & $165(3.7)$ & $19(2.6)$ \\
Men $\geq 15$ years & 1778 & 1342 \\
- At school & $277(15.6)$ & $193(14.4)$ \\
- Work, commuting daily & $178(10.0)$ & $140(10.4)$ \\
- Work, home on weekends & $69(3.9)$ & $59(4.4)$ \\
- Work in South Africa & $250(14.1)$ & $231(17.2)$ \\
- In the fields/herding & $465(26.2)$ & $373(27.8)$ \\
- Single day absence (not work-related) & $417(23.5)$ & $322(24.0)$ \\
- On holidays & $19(1.1)$ & $17(1.3)$ \\
- No information & $103(5.8)$ & $7(0.5)$ \\
Children & 2206 & 1228 \\
- At school & $1657(75.1)$ & $981(79.9)$ \\
- Work, commuting daily & $5(0.2)$ & $2(0.2)$ \\
- Work, home on weekends & $2(0.1)$ & $2(0.2)$ \\
- Work in South Africa & $3(0.1)$ & $3(0.2)$ \\
- In the fields/herding & $85(3.9)$ & $62(5.1)$ \\
- Single day absence (not work-related) & $244(11.1)$ & $161(13.1)$ \\
- No information & $14(0.6)$ & $12(1.0)$ \\
\hline
\end{tabular}

conducted only in rural areas. In the current study HTC uptake was substantially lower in urban areas, resulting in a lower overall coverage. Several studies, using a multi-disease approach, report uptake rates for HIV testing over 90\% [23-25]. A door to door HIV testing campaign conducted in neighboring KwaZulu Natal reports uptake rates of 76 and $86 \%$ in men and women respectively [26]. Of note, in our study, HTC uptake was similar in men and women (Table 3) - in contrast to many studies in similar settings, where generally men showed lower acceptance rates $[18,26]$. We are not able to comprehensively explain the similar HTC acceptance rates among women and men, but may assume that this is a characteristic of our setting, as we found the same result in a the previous study [12]. Men were, however, encountered less often at home, leading to a significantly lower HTC coverage among men. They were mostly absent due to travel, work in the field or work in neighboring South Africa (Table 2). During the SEARCH project in Uganda and Kenya, the fact that men's labor opportunities often require extended absences from home was frequently cited as a reason for lower testing coverage in men [27]. However, absence on the day of HTC may also have been caused by men not wanting to test for HIV. As communities were informed about the HTC campaign in advance, it is possible that some household members chose not to be home on the day of the campaign. In order to target men who were absent during home-based HTC, social network interventions, self-testing and testing at the workplace are promising interventions [28]. Moreover, the recent initiative of male-friendly clinics where male health care workers provide services has shown some first promising results [29]. Another approach may be to leave for household members who are absent an oral self-test kit [30]. As for men, it was also difficult to reach school-aged children. One approach might be to provide largescale school-based HTC. In a survey in South Africa, over $90 \%$ of parents supported HIV testing at schools [31].

Despite Lesotho having the second-highest HIV prevalence in the world, yield of new HIV diagnoses in our study was low with 4.2 and $4.0 \%$ in women and men respectively. However, considering all those encountered who already knew about their positive HIV status, adult prevalence in the population assessed was $18.8 \%$, which is similar to the reported adult HIV prevalence in Butha-Buthe of 17.8\% [15]. In line with the Lesotho population-based impact assessment (LePHIA) [15], our findings indicate that already in 2016 about $80 \%$ of HIV infected persons knew their status and $70 \%$ are taking ART. The encouraging fact that Lesotho is progressing towards the 90-90-90 targets, decreases the yield of newly tested positive individuals during home-based testing. Considering the yield of new HIV diagnoses, home-based testing may thus not be an efficient approach anymore [32]. However, several studies indicated that the benefit of home-based HTC should not only be seen in numbers newly found HIV positive as a negative HIV test may increase awareness and reduce riskbehavior [33]. Moreover, as indicated by high shares of first-time testers in our study, home-based HTC remains a valid approach to test persons who might not access testing otherwise. Furthermore, homebased HTC may serve to re-engage individuals who are known HIV positive but who never linked to care or dis-engaged from care. Furthermore, home-based 
Table 3 Likelihood of being encountered at home and HTC uptake according to age and gender

\begin{tabular}{|c|c|c|c|c|}
\hline & Total $n$ & n (\%) & Odds-ratio $(95 \% \mathrm{Cl})$ & $p$-value \\
\hline Total HH members & $18,286^{\mathrm{a}}$ & & & \\
\hline \multicolumn{5}{|l|}{ Ever encountered at home } \\
\hline - Women $\geq 15$ years & 7875 & $7130(90.5)$ & 1 & \\
\hline - Men $\geq 15$ years & 4807 & $3465(72.1)$ & $0.27(0.24-0.30)$ & $<0.001$ \\
\hline - Children $<15$ years & 5604 & $4376(78.1)$ & $0.37(0.33-0.41)$ & $<0.001$ \\
\hline HTC Uptake if encountered and not known HIV positive & 13,554 & $11,592(85.3)$ & & \\
\hline - Women $\geq 15$ years & 6119 & $5144(84.2)$ & 1 & \\
\hline - Men $\geq 15$ years & 3130 & $2613(83.5)$ & $0.95(0.84-1.07)$ & 0.38 \\
\hline - Children $<15$ years & 4314 & $3816(88.5)$ & $1.44(1.28-1.62)$ & $<0.001$ \\
\hline HTC coverage after 2 visits & $18,286^{\mathrm{a}}$ & $12,991(71.0)$ & & \\
\hline - Women $\geq 15$ years & 7875 & $6165(78.3)$ & 1 & \\
\hline - Men $\geq 15$ years & 4807 & $2948(61.3)$ & $0.44(0.41-0.48)$ & $<0.001$ \\
\hline - Children $<15$ years & 5604 & $3878(69.2)$ & $0.62(0.58-0.67)$ & $<0.001$ \\
\hline
\end{tabular}

${ }^{a} 50$ individuals were excluded from the table due to missing information on gender and/or age

HIV testing may be combined with services addressing other conditions, such as mother-and-child health, tuberculosis, mother-and-child health, and screening for viral hepatitis and other sexually transmitted diseases.

This study has several limitations. First, for calculating coverage, we used a broader definition of household member than earlier studies, and censoring of absent household members relied on reporting from those members who were found at home. Second, household members not encountered may well have been tested for HIV on another occasion, i.e. at their workplace in South Africa or at one of numerous testing-points within Lesotho. Finally, previous testing history relied on interviews and on information found in the health booklets of the household members.

\section{Conclusions}

In summary, during home-based HIV testing campaigns, a second catch-up visit during the weekend increased testing coverage in the whole community by about $9 \%$ and reached more first-time testers. However, the weekend catch-up visit increased cost per person tested and per person newly tested HIV positive considerably. Overall, even with a catch-up visit, testing coverage in the assessed communities fell short of the targeted $90 \%$. More research is needed about how to design more cost-effective HTC campaigns with a particular emphasis on providing different approaches for different population groups, e.g. by combining community- and home-based testing or introducing selftesting for those household members not encountered at home or refusing to test.

Table 4 HTC uptake and HIV prevalence among household members encountered at home who were not known to be HIV positive

\begin{tabular}{|c|c|c|c|c|c|c|c|}
\hline & $\mathrm{N}^{\mathrm{a}}$ & HTC uptake $\%$ & OR $(95 \% \mathrm{Cl})$ & $p$-value & Tested HIV $(\%)$ & OR $(95 \% \mathrm{Cl})$ & $\overline{p \text {-value }}$ \\
\hline Women $\geq 15$ years & 6110 & 84.2 & & & 4.2 & & \\
\hline Never tested & 1499 & 81.3 & Ref & & 4.3 & & \\
\hline$<12$ months ago & 2903 & 82.2 & $1.06(0.90-1.25)$ & 0.46 & 3.1 & $0.72(0.50-1.03)$ & 0.07 \\
\hline$\geq 12$ months ago & 1677 & 91.2 & $2.37(1.92-2.94)$ & $<0.001$ & 6.0 & $1.42(1.00-2.01)$ & 0.05 \\
\hline Men $\geq 15$ years & 3130 & 83.5 & & & 4.0 & & \\
\hline Never tested & 1188 & 82.0 & Ref & & 4.6 & & \\
\hline$<12$ months ago & 901 & 77.8 & $0.77(0.62-0.96)$ & 0.02 & 2.7 & $0.58(0.33-0.99)$ & 0.05 \\
\hline$\geq 12$ months ago & 1016 & 91.2 & $2.29(1.76-2.98)$ & $<0.001$ & 4.4 & $0.96(0.62-1.48)$ & 0.84 \\
\hline Children $<15$ years & 4314 & 88.5 & & & 0.6 & & \\
\hline Never tested & 2650 & 89.3 & Ref & & 0.8 & & \\
\hline$<12$ months ago & 863 & 85.1 & $0.68(0.55-0.85)$ & 0.001 & 0 & - & \\
\hline$\geq 12$ months ago & 769 & 91.0 & $1.20(0.91-1.56)$ & 0.20 & 0.3 & $0.35(0.08-1.53)$ & 0.16 \\
\hline
\end{tabular}

${ }^{\text {a}}$ From the total number, time since last HIV test was missing for 31 women, 25 men, and 32 children 


\section{Supplementary information}

Supplementary information accompanies this paper at https://doi.org/10. 1186/s12889-019-7784-z.

Additional file 1: Table S1. Unit cost used for cost-calculations. Salaries include additional cost as per legal requirement in Lesotho. Transport cost included fuel, vehicle insurance, tire replacement, car servicing and repair but not the purchase of the vehicle.

\section{Abbreviations}

AIDS: Acquired Immunodeficiency Syndrome; Cl: Confidence Intervall; HBHTC: Home-Based HIV Testing and Counselling; HH: Household; HIV: Human Immunodeficiency Virus; HTC: HIV Testing and Counselling; IQR: Interquartile Range; OR: Odds Ratio; UNAIDS: Joint United Nations Programme on HIV/ AIDS; WHO: World Health Organization

\section{Acknowledgements}

The authors would like to thank all study participants and the village authorities who consented for home-based HTC to happen in their villages. The authors would further like to acknowledge Miss Phofu, Miss Ntoiseng, Miss Tsepang and Miss Kamele for their contribution to the organization of the HTC campaigns. This manuscript is dedicated to Miss Christiane Fritz who had a key-role in design and preparation of this study but sadly passed away before completion of the manuscript.

\section{Authors' contributions}

NDL was the principal investigator of the CASCADE-trial and wrote the first draft of the manuscript. TRG contributed to study design and was responsible for data-management and statistical analyses. IR and TIL were responsible for the conduction of campaigns and supervised lay-counsellors. AA, IR, JW, TIL, TK and TRG contributed to data collection and interpretation and commented on the manuscript. All authors have read and approved the final version of the manuscript.

\section{Funding}

This study was funded by grant R4D Open Call IZO7Z0_160876/1 from the Swiss National Science Foundation (SNSF) and the Stiftung für Infektiologie beider Basel. NDL receives his salary through a SNSF Eccellenza Professorship grant (PCEFP3_181355). AA receives his salary through a grant from the MDPhD programme of the SNSF (323530_177576).

Funding institutions had no role in design, analysis and publication of this study.

\section{Availability of data and materials}

Upon request to the co-author responsible for data-management and statistical analysis (TRG)

\section{Ethics approval and consent to participate}

The protocol has been approved by the Ethical Board in Switzerland (Ethikkommission Nordwestschweiz; EKNZ UBE 15/123) and the National Health Research and Ethics Committee of the Ministry of Health of Lesotho (89-2015). Heads of household provided written informed consent for the study-team to enter the households. Thereafter all household members present who participated provided written informed consent. In case of participants $<18$ years of age, a parent or legal caregiver provided written consent.

\section{Consent for publication}

Not applicable.

\section{Competing interests}

The authors declare that they have no competing interests.

\section{Author details}

'Department of Medicine, Swiss Tropical and Public Health Institute, Basel, Switzerland. ${ }^{2}$ Infectious Diseases and Hospital Epidemiology, University Hospital Basel, Basel, Switzerland. ${ }^{3}$ University of Basel, Basel, Switzerland. ${ }^{4}$ SolidarMed, Swiss Organization for Health in Africa, Maseru, Lesotho. ${ }^{5}$ Molecular Virology, Department of Biomedicine, Basel, Switzerland.
Received: 2 May 2019 Accepted: 16 October 2019

Published online: 01 November 2019

\section{References}

1. UNAIDS (2016) On the Fast-Track to end AIDS: UNAIDS 2016-2021 Strategy. Accessed 4 Oct 2016 http://www.unaids.org/sites/default/files/media_ asset/20151027_UNAIDS_PCB37_15_18_EN_rev1.pdf

2. Iwuji C, Newell M-L. Public health action. HIV test "front door" to UNAIDS 90-90-90 target 7:79; 2017.

3. Unaids (2018) UNAIDS DATA 2018.

4. World Health Organization Planning, implementation and monitoring home-based HIV testing and counselling. A practical handbook for Subsaharan Africa. Available at: http//apps.who.int/iris/bitstream/10665/ 75366/1/9789241504317_eng.pdf.

5. WHO (2015) Consolidated guidelines on HIV testing services. World Heal. Organ.

6. Sharma M, Ying R, Tarr G, Barnabas R. Systematic review and meta-analysis of community and facility-based HIV testing to address linkage to care gaps in sub-Saharan Africa. Nature. 2015;528:S77-85.

7. Molesworth AM, Ndhlovu R, Banda E, Saul J, Ngwira B, Glynn JR, Crampin AC, French N. High accuracy of home-based community rapid HIV testing in rural Malawi. J Acquir Immune Defic Syndr. 2010;55:625-30.

8. Wachira J, Ndege S, Koech J, Vreeman RC, Ayuo P, Braitstein P. HIV testing uptake and prevalence among adolescents and adults in a large homebased HIV testing program in Western Kenya. J Acquir Immune Defic Syndr. 2014;65:e58-66.

9. Petersen M, Balzer L, Kwarsiima D, et al. Association of implementation of a universal testing and treatment intervention with HIV diagnosis, receipt of antiretroviral therapy, and viral suppression in East Africa. JAMA. 2017;317: 2196-206.

10. UNAIDS (2019) UNAIDS DATA 2019. Accessed 12 Sept 2019 https://www. unaids.org/sites/default/files/media_asset/2019-UNAIDS-data_en.pdf

11. Joint United Nations Programme on HIV/AIDS (UNAIDS) (2017) UNAIDS Data 2017. http://www.unaids.org/sites/default/files/media_asset/20170720_ Data_book_2017_en.pdf

12. Labhardt ND, Motlomelo M, Cerutti B, Pfeiffer K, Kamele M, Hobbins MA Ehmer J. Home-based versus Mobile clinic HIV testing and counseling in rural Lesotho: a cluster-randomized trial. PLoS Med. 2014. https://doi.org/10. 1371/journal.pmed.1001768.

13. Labhardt ND, Ringera I, Lejone TI, Klimkait T, Muhairwe J, Amstutz A, Glass TR. Effect of offering same-day ART vs usual health facility referral during home-based HIV testing on linkage to care and viral suppression among adults with HIV in Lesotho: the CASCADE randomized clinical trial. JAMA - J Am Med Assoc. 2018. https://doi.org/10.1001/jama.2018.1818.

14. Labhardt ND, Ringera I, Lejone TI, et al. Same day ART initiation versus clinic-based pre-ART assessment and counselling for individuals newly tested HIV-positive during community-based HIV testing in rural Lesotho - a randomized controlled trial (CASCADE trial). BMC Public Health. 2016. https://doi.org/10.1186/s12889-016-2972-6.

15. Ministry of Health L. Lesotho population-based HIV impact assessment (LePHIA) summary sheet: preliminary findings; 2017. p. 1-6.

16. Bemelmans $M$, Baert $S$, Negussie $E$, Bygrave $H$, Biot $M$, Jamet $C$, Ellman $T$, Banda A, van den Akker T, Ford N. Sustaining the future of HIV counselling to reach 90-90-90: a regional country analysis. J Int AIDS Soc. 2016;19:20751.

17. Government of Lesotho. National guidelines on the use of antiretroviral therapy for HIV prevention and treatment. 5th ed; 2016.

18. Chamie G, Clark TD, Kabami J, et al. A hybrid mobile approach for population-wide HIV testing in rural East Africa: an observational study. Lancet HIV. 2016;3:e111-9.

19. Kadede K, Ruel T, Kabami J, et al. Increased adolescent HIV testing with a hybrid mobile strategy in Uganda and Kenya. AIDS. 2016;30:2121-6.

20. Asiimwe S, Ross JM, Arinaitwe A, Tumusiime O, Turyamureeba B, Roberts DA, O'Malley G, Barnabas RV. Expanding HIV testing and linkage to care in southwestern Uganda with community health extension workers. J Int AIDS Soc. 2017;20:80-7.

21. Chang W, Chamie G, Mwai D, et al. Implementation and operational research: cost and efficiency of a hybrid Mobile multidisease testing approach with high HIV testing coverage in East Africa. J Acquir Immune Defic Syndr. 2016;73:e39-45.

22. Pegurri E, Fox-Rushby JA, Damian W. The effects and costs of expanding the coverage of immunisation services in developing countries: a systematic literature review. Vaccine. 2005;23:1624-35. 
23. Lugada E, Millar D, Haskew J, et al. Rapid implementation of an integrated large-scale HIV counseling and testing, malaria, and diarrhea prevention campaign in rural Kenya. PLoS One. 2010;5:e12435.

24. Chamie G, Kwarisiima D, Clark TD, et al. Leveraging rapid community-based HIV testing campaigns for non-communicable diseases in rural Uganda. PLoS One. 2012;7:e43400.

25. Chamie G, Kwarisiima D, Clark TD, et al. Uptake of community-based HIV testing during a multi-disease health campaign in rural Uganda. PLoS One. 2014;9:e84317.

26. Lewis L, Maughan-Brown B, Grobler A, Cawood C, Khanyile D, Glenshaw M, Kharsany ABM. Impact of home-based HIV testing services on Progress toward the UNAIDS 90-90-90 targets in a Hyperendemic area of South Africa. JAIDS J Acquir Immune Defic Syndr. 2019;80:135-44.

27. Camlin CS, Ssemmondo E, Chamie G, et al. Men "missing" from populationbased HIV testing: insights from qualitative research. AIDS Care. 2016; 28(Suppl 3):67-73.

28. Yamanis TJ, Dervisevic E, Mulawa M, Conserve DF, Barrington C, Kajula LJ, Maman S. Social network influence on HIV testing among urban men in Tanzania. AIDS Behav. 2017;21:1171-82.

29. PEPFAR Male-Friendly Clinics in Lesotho: Demand Creation Targeting HIVInfected Men to Access Comprehensive Health Services - PEPFAR Solutions Platform (BETA). https://www.pepfarsolutions.org/solutions/201 8/11/6/male-friendly-clinics-demand-creation-targeting-hiv-infected-men-toaccess-comprehensive-health-services. Accessed 1 Jul 2019.

30. Amstutz A, Lejone TI, Khesa $L$ (2019) The HOSENG trial - effect of the provision of oral self-testing for absent and refusing individuals during a door-to-door HIV-testing campaign on testing coverage: protocol of a cluster-randomized clinical trial in rural Lesotho. Trials in press:

31. Madiba S, Mokgatle M. Parents support implementation of HIV testing and counseling at school: cross-sectional study with parents of adolescent attending high School in Gauteng and North West Provinces, South Africa. AIDS Res Treat. 2016;2016:4842814.

32. De Cock KM, Barker JL, Baggaley R, El Sadr WM. Where are the positives? HIV testing in sub-Saharan Africa in the era of test and treat. AIDS. 2019;33: 349-52.

33. Sulat JS, Prabandari YS, Sanusi R, Hapsari ED, Santoso B. The impacts of community-based HIV testing and counselling on testing uptake. J Heal Res. 2018;32:152-63.

\section{Publisher's Note}

Springer Nature remains neutral with regard to jurisdictional claims in published maps and institutional affiliations.

Ready to submit your research? Choose BMC and benefit from:

- fast, convenient online submission

- thorough peer review by experienced researchers in your field

- rapid publication on acceptance

- support for research data, including large and complex data types

- gold Open Access which fosters wider collaboration and increased citations

- maximum visibility for your research: over $100 \mathrm{M}$ website views per year

At $\mathrm{BMC}$, research is always in progress.

Learn more biomedcentral.com/submissions 